\title{
Evaluation of A University-Based Bullying and Cyberbullying Prevention Program
}

\author{
Elizabeth Englander ${ }^{1}$, Katalin Parti ${ }^{2}$, Meghan McCoy ${ }^{1}$ \\ (1. The Massachusetts Aggression Reduction Center, Bridgewater State University, USA \\ 2. The National Institute of Criminology, Hungary)
}

\begin{abstract}
An independent evaluator spent an academic year evaluating a unique bullying and cyberbullying prevention program in Massachusetts: an academic Center utilizing students and faculty to bring high-quality, no-cost programming to primary and secondary education. Quantitative and qualitative findings suggest that the program's elements that are most effective and helpful are its emphasis on research findings, especially research on digital problems; its use of high-status peers and positive strategies for student programs; and its focus on practical and concrete tips and strategies. Although the evaluation was conducted with the goal of adopting the model in Hungary, suggestions from Budapest pointed to significant obstacles that remain before such an adoption could be successful.
\end{abstract}

Key words: bullying, cyberbullying, aggression, research, psychology, evaluation

\section{Introduction}

On Google Scholar, a search for the term bullying produces more than 350,000 scholarly articles on the topic. Clearly, research and practice in bullying and cyberbullying prevention are flourishing; yet demand for field programming remains high, and stubborn obstacles conspire to prevent a sense of widespread success. One of the largest impediments may actually be the sheer volume of variable-quality information available to primary and secondary school educators who are seeking high-quality, research-based programming for bullying and cyberbullying prevention. Many of these educators, faced with a veritable tsunami of data, are overwhelmed by (and may even decide to avoid) the subject of bullying. Understanding bullying and cyberbullying involves both learning new topics and reminding ourselves about the underlying issues and techniques that have always been germane, but are sometimes forgotten in the cascade of anxiety and information overload that accompanies a constantly publicized social problem. However, it's important to remember that many of the messages and prevention efforts we already know about bullying remain the cornerstones of our efforts to reduce it. The goal in bullying prevention is still equable, civilized, self-controlled behavior among children, even when angry or irritated (actually, especially when angry or irritated). The tools are still knowledge and awareness about the impact of cruel behaviors on others, ways to intervene and help, healthy and successful relationships, and, today, a

Elizabeth Englander, Ph.D., Professor, Bridgewater State University; research areas/interests: bullying, cyberbullying, digital behaviors. E-mail: EENGLANDER@bridgew.edu.

Katalin Parti, Ph.D., Institute of Criminology; research areas/interests: cyberbullying and cyber-behaviors.

Meghan McCoy, Ph.D., Professor, Bridgewater State University; research areas/interests: bullying and cyberbullying. 
good grasp of how digital communications are different from more traditional forms of social interaction. The mechanisms remain clear and effective education, an eye trained on the different developmental needs of children, the emotional connections we make with our students, and our common sense.

Most bullying and cyberbullying prevention efforts in the United States today are led by independent non-profits (or, occasionally, for-profit ventures), with varying degrees of expertise in the fields for which they offer training. These independent agencies may not utilize research-based approaches (they may lack training, research expertise, or the resources to bring in independent evaluators); they may not have a developmentally-based approach, sensitive to different, age-appropriate approaches for children at different stages; they may not involve the entire community in the trainings, despite long-held and well-established best-practices that emphasize whole-school approaches; and they may have "techno-phobia," or difficulty integrating both in-person and digital social behaviors. (Likewise, agencies that specialize in digital technology education may lack an understanding of child development.). The limitations inherent in this system encouraged the foundation of the Massachusetts Aggression Reduction Center, developed in 2004.

Utilizing a research-based approach is not a black-and-white issue, nor should it be regarded as such. A handful of social and emotional learning programs have highest-quality, double-blind, experimental data demonstrating different degrees of efficacy. Many other programs have varying types and degrees of data suggesting impact; some may rely on outcome surveys, or observational data, or correlational relationships. Digital behaviors and mechanisms change so rapidly as to defy traditional experimental research examination (i.e., the time needed to complete, analyze, and publish research typically renders any digital activities studied as obsolete or, at best, dated). Yet even in the experimental research studies, measuring concepts such as bullying and cyberbullying is very challenging. Does a decrease in bullying reports following the implementation of a program indicate fewer cases of bullying, or simply fewer reports (which could in fact indicate a worsening of the problem, not the opposite)? What if adults see a difference, but children do not? Self-report data about bullying has methodological limitations, but the limitations of official reports of bullying are probably even greater. Of course, studies with cultural differences may not be comparable and cross-study analysis can result in a false picture of the matter under scrutiny (van de Vijver \& Chasiotis, 2010). How can a school administrator in a primary or secondary school sift through these differences and evaluate the different data, with all its measurement, sampling, and statistical differences? Yet in spite of these difficulties, it is clearly preferable for programs to offer some level of research and evaluation, and to publish that evaluation so that it is readily available to the scientific and education community.

The role of research in prevention programs is not confined to evaluating efficacy. Relevant programming must be grounded in current research on the nature and causes of bullying and cyberbullying. For example, the nature of bullying itself has changed in the last two decades. The major changes are the shift from physical to predominantly psychological bullying, and the ways that cyberbullying and cyber behaviors interact with the social lives of children today (Coulter, Kessel, Schneider, O’Donnell, \& Stueve, 2011; Finkelhor, Turner, Ormrod, \& Hamby, 2010; Vaillancourt, Hymel, \& McDougall, 2003). These changes, in turn, mean that adults must change their prevention efforts. For example, programs that rely on the concept that victims should be able to defend themselves physically may no longer be relevant. The shift to psychological bullying means that children today overwhelmingly express contempt in the form of common misbehaviors such as name-calling, gossip, eye-rolling, whispering about the target in front of them, etc. Of course, these behaviors are frequently used in situations that are not bullying, but they are nonetheless present in the vast majority of bullying incidents 
(Englander, 2013). This fact, uncovered in more recent research, means that adults may not recognize bullying when it happens in front of them. If a teacher sees two students whispering in front of a third, how can they possibly know if it's the first and only time this has happened, or part of an ongoing campaign against that child? Such key points are only understood by programs that immerse themselves in the most recent research findings.

Possibly the most challenging area of change that should be reflected in current programming is the impact of digital technology on antisocial interactions between children. Digital communication presents its own, more recent, demands on those seeking to deliver effective bullying prevention programs. Although there is a tendency to regard digital socializing as either irrelevant, or totally separate from, in-person bullying, data in fact suggests that the two types of socializing strongly interact and affect each other, particularly, but not exclusively, among middle- and high-school-aged children (Englander, 2012). Cyberspace is just another place with children see and interact with their peers, yet it is qualitatively different - a place where conflict can easily emerge (frequently from misunderstandings), where emotions can quickly escalate, where users are markedly disinhibited, and where bystanders can jump into others' social conflicts with both feet, intensifying the situation in a way that would not necessarily happen in person. Despite these ramifications, vast swaths of prevention programming continue to completely ignore the role that digital communications can play in the social lives of children today (both positively and negatively). The narrowness of this approach is only complicated by the fact that knowledge about digital communications has only been investigated in the research lab relatively recently. Not having a firm handle on that recent research can make it difficult to accept new realities, especially those that gallop at lightning speed across our landscape (as the digital revolution has).

Another issue challenging bullying prevention efforts is the need to develop and test comprehensive training and materials for different populations. Decades ago, Dan Olweus noted the importance of the "whole-school" method of bullying prevention (Olweus, 1993). Although many programs and materials are developed for children, this method underlines the fact that they are not the only population that needs to be trained in a school community; parallel and complementary training and materials need to be developed for faculty, staff, administration, parents, and students. In Massachusetts, we have also found it very beneficial to train other stakeholders who care for children (e.g., pediatricians) (Englander, 2012). Even within the population of students, children at different stages of development exhibit markedly different needs and different challenges, which necessitates different trainings and materials and an understanding of child development. A focus on developmental issues has always been an important part of bullying prevention, and it remains so today. How do bullying and cyberbullying change as children grow and develop? A developmental focus can help practitioners assess what children need at different ages to develop the social skills necessary to avoid and cope with antisocial peers. Clearly, not all who work in technology education or social and emotional learning have expertise in child development specifically or the ability, time, or resources to develop a multitude of different programs for children of different ages. Adolescent children can be particularly complex as they remain emotionally immature but are poised to, and interested in, being directly involved in solving their own social challenges. Yet most programs continue to have adults (not peers) who lecture teens, instead of preparing them to take the lead through the use of student-led and student-centered programs (which are, admittedly, more time-intensive for the adult supervisors).

The Massachusetts Aggression Reduction Center (MARC) was developed to address these obstacles and others, such as schools' budgetary limitations and the lack of bullying and cyberbullying prevention training in prospective educators and counselors. MARC is a center housed at a public university in Massachusetts, staffed 
by faculty and students, that brings education, training, curricula, research, and other resources to the primary and secondary education community and other stakeholders (e.g., pediatric physicians, social workers, attorneys, etc.). The primary goals of the Center are twofold: first, to bring research-based, high-quality, developmentally appropriate bullying and cyberbullying prevention programming to local stakeholders, usually at no cost to them; and second, to train future educators and counselors (in the form of University students studying for graduate and undergraduate degrees in relevant fields). To achieve these goals, MARC employs its University setting to both stay on top of other researchers' work and to conduct and disseminate cutting-edge research on bullying and cyberbullying. MARC faculty deliver training programs for K-12 faculty, administrators, and staff, and trained MARC students spearhead training and education for children and adolescents. In Hungary, it was recognized that programs such as MARC's could function as model approaches to better prepare Hungarian schools, if, following adequate evaluation, they prove effective.

How successful and effective is this approach to bullying prevention? It clearly helps avoid some of the obstacles present in the field today, notably fiscal concerns (schools do not have to pay for most programs from MARC), quality of programming, and the need to train future educators and counselors. Outcomes data has been gathered regularly by MARC researchers, but such data is limited by its nature (i.e., being a self-assessment). Clearly, there was a need for an in-depth, independent evaluation of MARC programs. During 2013-2014, the Fulbright Foundation and the Hungarian Eötvös Scholarship funded an independent researcher to study MARC's programs and approach for an entire year, gather new data on outcomes, and evaluate the resulting evidence for efficacy. This paper presents both the quantitative and qualitative results of that independent evaluator (Dr. Katalin Parti, of the National Institute of Criminology, Hungary) and other relevant but informal sources of data on effectiveness.

\section{Background Information}

Anti-bullying and Internet education and awareness raising programs started in the early 1990s in the United States. Social and emotional learning programs that increase students' underlying skills in assertion, impulse control, empathy, conflict resolution, and restorative practices remain in use today, and in some states such programming is mandated by law. In contrast, aggression reduction and digital literacy programs are still only in the beginning phases in Eastern European countries, including the former Yugoslavian countries, the Czech Republic, Slovakia, Romania, Bulgaria or Hungary, where internet penetration is still significantly lower (except among youth) and where bullying and cyberbullying are not recognized as serious issues that require research support (in the form of longitudinal studies) or that need to be dealt with specifically at school (Livingstone \& Haddon, 2009: 247; Lobe et al., 2009; Staksrud, 2009; Hasebrink et al., 2009).

\subsection{Evaluation of Faculty Training Programs}

The faculty training programs offered by the Massachusetts Aggression Reduction Center are distinctive in that they focus much less on broader, social causes of behavior problems (e.g., poverty) and more on immediate causes (e.g., social status or anger), and, in addition, much more on concrete, practical steps that educators can take to respond to bullying and cyberbullying and to prevent these problems. MARC's programs also draw heavily from current research and are much less theoretical; faculty are not simply told what to do - they are shown the data and research findings as an explanation of why certain responses are recommended. This strong research emphasis also allows the review of more cutting-edge digital issues, such as sexting, self-cyberbullying, 
and other digital social challenges.

Massachusetts law mandates primary and secondary school faculty training annually in bullying and cyberbullying prevention and intervention. Faculty training programs in MARC are conducted both through direct in-service trainings and through a Train-the-Trainer model. A direct in-service is a three hour workshop presented at a school site, which all onsite faculty and staff are required to attend. During a Train the Trainer workshop, schools send potential Trainers to MARC, where they are exposed to the same three hour workshop, plus an additional module to help them learn how to train their colleagues. Here, we will present the evaluation data gathered on attendees at a Train-the-Trainer workshop, covering both the three hours of faculty training and the additional Trainers' module.

The three hour workshop focuses on issues such as the scope of the problems, challenges that may impede progress on bullying and cyberbullying prevention, the latest significant research outcomes, and how students and adults (faculty and parents respectively) see the core of the problem - types of bullying and cyberbullying behaviors, what works and what are the techniques to be avoided at the school's anti-bullying program. For the Trainers, a second module occurs after the content delivery, where there is an interactive phase during which the participants can rehearse presenting, practice overcoming common difficulties, review technical challenges, ask questions, and discuss controversial issues.

\subsection{Methodology for the Evaluation of the Faculty Training}

Altogether 84 school staff members (teachers, school psychologists, education consultants) participated at the Train-the-Trainer model workshop for education professionals on two separate occasions (November and December 2013) in Massachusetts. The participants were filled out a questionnaire at the beginning of the day, and then after the program (a pre-test and post-test design), which enabled us to compare their expectations for the training and their general satisfaction as regards to how the training curriculum met these expectations. The participants were also given semi-structured questions during the post-test that permitted us to gather qualitative data in the form of open-ended questions.

Because MARC's faculty training model focuses heavily on current research and practical strategies, much of the evaluation focuses on those features.

\subsection{Results of the Evaluation of the Faculty Training}

Table 1 (below) shows the results of the comparison between attendee expectations and outcomes. Overall, the training modestly exceeded expectations, with subjects reporting that they had gained knowledge beyond their initial expectations. There was variation between the specific elements tested. The largest positive differences between pre-test expectations and post-test outcomes occurred for subjects who wanted to develop a better understanding of cyberbullying, to learn to differentiate between bullying and other types of conflicts, to learn information related to specific problems occurred in my school, to learn how to early recognize potential cyberbullying problems, and to learn how to help resolve problems.

The variables for which the content did not meet expectations were the information on helping parents deal with bullying and the information on helping students resolve incidents of cyberbullying. Participants were more interested in why children make immature decisions and why the experience of being bullied can be so painful and irreparable for victims (see Table 1). 
Table 1 Participant gains during training (expected vs achieved)

\begin{tabular}{|c|c|c|c|}
\hline Statement & Expected (n) & Gained (n) & $\begin{array}{l}\text { How much the } \\
\text { Gains Exceeded } \\
\text { the Expectations? } \\
\text { (Pre- and Post Test } \\
\text { of Participants) }\end{array}$ \\
\hline I am not particularly interested & 1 & 1 & 0 \\
\hline I am generally interested & 4 & 7 & +3 \\
\hline $\begin{array}{l}\text {...to learn information related to specific problems occurred in my } \\
\text { school }\end{array}$ & 32 & 44 & +12 \\
\hline ...to learn how (cyber) bullying influence school climate & 65 & 64 & -1 \\
\hline $\begin{array}{l}\text {...to learn the side effects of (cyber) bullying and how pupils } \\
\text { experience them }\end{array}$ & 55 & 57 & +2 \\
\hline ...to learn how to avoid premature decisions & 57 & 53 & -4 \\
\hline ...to be better able to help parents in understanding and solving & 66 & 59 & -7 \\
\hline ...to learn how to help pupils solve (cyber) bullying more effectively & 67 & 55 & -12 \\
\hline ...to learn what educators can do when confronting such problems & 65 & 68 & +3 \\
\hline $\begin{array}{l}\text {...to learn to differentiate between bullying and other types of } \\
\text { conflicts }\end{array}$ & 61 & 77 & +16 \\
\hline ...to learn how to early recognize potential (cyber) bullying problems & 67 & 74 & +7 \\
\hline ...to learn how to help resolve problems & 65 & 72 & +7 \\
\hline ...to develop a better understanding of (cyber) bullying & 65 & 80 & +25 \\
\hline \multicolumn{3}{|c|}{ Mean (How much the gains exceeded the expectations?) } & +3.6 \\
\hline
\end{tabular}

Several of these "weaker" elements were, however, highly correlated with other elements that were more strongly rated. There are high significant Pearson correlations between the following values:

- Knowledge gained on what an educator can do when confronting problems related to bullying and cyberbullying AND how to help pupils resolve these situations $\left(\mathrm{r}^{2}=.456 ; \mathrm{p}<.000\right)$;

- Knowledge gained on the side effects of bullying and cyberbullying and how pupils experience them AND how to help pupils resolve (cyber) bullying situations $\left(\mathrm{r}^{2}=.525 ; \mathrm{p}<.000\right)$

- Knowledge gained on how to avoid premature decisions AND information related to specific problems occurred in my school $\left(\mathrm{r}^{2}=.464 ; \mathrm{p}<.000\right)$

- Knowledge gained on how bullying and cyberbullying influence school climate AND how to avoid premature decisions $\left(\mathrm{r}^{2}=.512 ; \mathrm{p}<.000\right)$

These relationships suggest that addressing all of these variables individually, in detail, may not be necessary in effective training. The answers suggest that the participants value information highly when it helps them to understand students' feelings and motivations, and they appreciate information on how to help pupils resolve difficult situations.

For most respondents (53 in 83), this was not their first experience of an anti-bullying program. This fact enabled them to compare the MARC program to others they had experienced. In comparison with other programs, this faculty training received excellent marks. The participants were generally satisfied with the training - they particularly appreciated the trainer's preparedness, the availability of the curriculum and the smoothly conducted registration before the training. The intelligibility and logical structure of the curriculum received the highest praise, but the program also received a positive evaluation regarding its organization, and the problem solving methods offered, in comparison with other programs (see Table 2). 
Table 2 Participant satisfaction with training

\begin{tabular}{|l|l|l|l|l|l|l|}
\hline How satisfied the participant was with the Train-the-Trainer workshop? \\
\hline & $\begin{array}{l}1 \text { (not satisfied } \\
\text { at all) }\end{array}$ & $\begin{array}{l}2 \text { somewhat } \\
\text { satisfied) }\end{array}$ & $\begin{array}{l}\text { (satisfied } \\
\text { enough) }\end{array}$ & $\begin{array}{l}4 \text { (very } \\
\text { satisfied) }\end{array}$ & No answer & Total \\
\hline Was the program well organized? & $0(0.0 \%)$ & $1(1.2 \%)$ & $10(11.9 \%)$ & $73(86.9 \%)$ & $0(0.0 \%)$ & $84(100.0 \%)$ \\
\hline Were the topics relevant? & $0(0.0 \%)$ & $5(6 . \%)$ & $11(13.1 \%)$ & $68(81.0 \%)$ & $0(0.0 \%)$ & $84(100.0 \%)$ \\
\hline $\begin{array}{l}\text { Was at least 25\% of the material } \\
\text { new or new perspective? }\end{array}$ & $1(1.2 \%)$ & $9(10.7 \%)$ & $30(35.7 \%)$ & $44(52.4 \%)$ & $0(0.0 \%)$ & $84(100.0 \%)$ \\
\hline Were the trainers informative? & $0(0.0 \%)$ & $1(1.2 \%)$ & $3(3.6 \%)$ & $80(95.2 \%)$ & $0(0.0 \%)$ & $84(100.0 \%)$ \\
\hline Were the trainers prepared? & $0(0.0 \%)$ & $0(0.0 \%)$ & $2(2.4 \%)$ & $82(97.6 \%)$ & $0(0.0 \%)$ & $84(100.0 \%)$ \\
\hline $\begin{array}{l}\text { Was the material presented in an } \\
\text { understandable way? }\end{array}$ & $0(0.0 \%)$ & $2(2.4 \%)$ & $8(9.5 \%)$ & $74(88.1 \%)$ & $0(0.0 \%)$ & $84(100.0 \%)$ \\
\hline $\begin{array}{l}\text { Were the questions handled } \\
\text { satisfactorily? }\end{array}$ & $1(1.2 \%)$ & $3(3.6 \%)$ & $22(26.2 \%)$ & $58(69.0 \%)$ & $0(0.0 \%)$ & $84(100.0 \%)$ \\
\hline Was the room adequate? & $1(1.2 \%)$ & $13(15.5 \%)$ & $36(42.9 \%)$ & $34(40.5 \%)$ & $0(0.0 \%)$ & $84(100.0 \%)$ \\
\hline Was the food adequate? & $1(1.2 \%)$ & $3(3.6 \%)$ & $16(19.0 \%)$ & $64(76.2 \%)$ & $0(0.0 \%)$ & $84(100.0 \%)$ \\
\hline $\begin{array}{l}\text { Were the starting and ending } \\
\text { times convenient? }\end{array}$ & $1(1.2 \%)$ & $0(0.0 \%)$ & $13(15.5 \%)$ & $70(83.3 \%)$ & $0(0.0 \%)$ & $84(100.0 \%)$ \\
\hline $\begin{array}{l}\text { Was your registration handled } \\
\text { smoothly? }\end{array}$ & $1(1.2 \%)$ & $2(2.4 \%)$ & $5(6.0 \%)$ & $75(89.3 \%)$ & $1(1.2 \%)$ & $84(100.0 \%)$ \\
\hline
\end{tabular}

In addition, most (81\%) of the participants found that it was worth coming to the training, and $78 \%$ would also recommend the program to others. Interestingly, only $55 \%$ of the respondents believed that they were in general more prepared on the topic by the end of the workshop. Although this appears to contradict other information, some clarification about the contrast in these findings can be seen in the qualitative data gathered through the open questions: notably, the participants felt they needed more time to "digest" the high volume of information they received at the training. Overall, $67 \%$ of the participants felt they were, in fact, more knowledgeable at the end of the workshop.

Half of the participants had already participated in other Train the Trainer workshops of MARC (i.e., they had been certified in previous years), and their opinion was positive in relation to the program's quality and the use of the latest research findings to support it. The Trainers who had participated in faculty trainings with other programs (not run by MARC) gave unanimously positive feedback on the organization of the program and its practical usefulness in comparison to those other anti-bullying programs.

The strong emphasis on research-based content is of particular interest in this model. In general, the content of the workshop earned excellent marks: $83.3 \%$ of the participants answered that they were "satisfied enough" or "very much satisfied" with the substance of the training (the program was well organized, the topics were relevant, at least $25 \%$ of the material was new or offered a new perspective to them, the trainers were informative, understandable and prepared, and the questions were handled satisfactory). Only $16.7 \%$ scored the training as worse than "satisfactory enough". The logistics of the training gained somewhat lower scores, as $77.4 \%$ said the room and the food offered were adequate, the timeframe was convenient, and the registration was handled smoothly; the other $22.6 \%$ gave lower scores ("not satisfactory" or "only somewhat satisfactory") and expressed some concerns (Table 3).

Table 3 Participant satisfaction with faculty training 


\begin{tabular}{|l|l|l|}
\hline \multicolumn{2}{|l|}{ Level of satisfaction with the training (answered "satisfactory enough" or "very much satisfactory") } \\
\hline & yes & no \\
\hline Overly satisfied with the substance of the training & $70(83.3 \%)$ & $14(16.7 \%)$ \\
\hline Overly satisfied with the logistics of the training & $65(77.4 \%)$ & $19(22.6 \%)$ \\
\hline
\end{tabular}

The participants gave a detailed explanation of their critical remarks in their responses to open questions, noting among other things that the time management should be better - the first half of the training is apparently too dense, the participants have to take in too many details, while in the 2 hours following the content training, they would like to receive even more practical content. This information is critical, as MARC's model relies heavily (as stated previously) on current research and practical strategies. It is heartening that subjects want even more time for research and more strategies, as that suggests the approach overall answers their needs; but it does critically identify a need for more time to cover that research, and more content about tactics specifically. Interestingly, subjects did not object to the absence of a more theoretical discussion, or a lack of discussion of broader social issues that (without question) contribute to bullying and cyberbullying.

\subsection{Evaluation of Student Programming}

The Center's programs are developmentally-based and age-appropriate, and use college students as high-status peers to deliver anti-bullying messages to their younger peers. University students, who receive course credits for their work in MARC, are powerful role models to younger students in a way that many older authority figures (such as parents and teachers) cannot be. They help high school and middle school students learn how to recognize and label the problems they see, and how to consider ways they can lead an effort in their specific school culture to work against violence and bullying. Neither the problems nor the solutions are entirely defined or imposed by adults.

The Massachusetts Aggression Reduction Center provides different types of training for primary and secondary students. Some are delivered as direct in-services in schools, while for other trainings, students travel to the University. The student assembly programs for K-12 schools are 45-minute, interactive presentations provided by graduate students trained by MARC. Presentations are age-appropriate and different topics are covered at different ages (e.g., "sexting" (taking and sending naked pictures) is not discussed until 7th grade). Student programming in MARC is distinctive in that it is delivered by students and not by professionals, who can be viewed as authority figures. Students, in contrast, are more likely to be viewed as high-status peers. In addition, the student programs cover negative behaviors but emphasize positive behaviors (e.g., they do not simply tell children not to bully, but cover a variety of ways students can help and similar-age students who have been featured in the media for actively engaging in positive bullying prevention activities).

The content of the student programs is designed to help children develop the appropriate vocabulary to understand and deal with bullying issues in schools. Children are introduced to roles and emotional responses associated with bullying. Productive ways to deal with bullying and cyberbullying are discussed and there is also a discussion of the differences between conflict and fighting, accidents that may happen, and bullying or cyberbullying.

\subsection{Methodology of the Student Program Evaluation}

Teachers are required to attend the student programs, along with their pupils. The importance of consistency of information across students and adults is emphasized to schools when the programs are arranged with MARC. 
The evaluation is based on several assemblies held for 6-8 graders, and their teachers, at Blanchard Middle School in Westford, Massachusetts. The school volunteered to participate in the evaluation, and the analysis involved anonymous, self-report, pre- and post-questionnaires. The pre-test was completed by 380 students and the post-test was completed by 368 students from the $6^{\text {th }}$ and the $7^{\text {th }}$ grades. The post-test was conducted within $2-3$ weeks after the assembly was held. Very little attrition occurred between pre- and post-test. The grade and the gender distribution were almost equal and can be seen below in Table 4.

Table 4 Numbers of students participating in Pre- and Post-test evaluations

\begin{tabular}{|c|c|c|c|c|c|}
\hline \multicolumn{6}{|c|}{ Students participating in both test phases } \\
\hline & \multicolumn{2}{|c|}{ Grade } & \multicolumn{3}{|c|}{ Gender } \\
\hline & $6^{\text {th }}$ grade & $7^{\text {th }}$ grade & Boys & Girls & N.A. \\
\hline PRE test phase & $188(49.5 \%)$ & $192(50.5 \%)$ & $199(52.4 \%)$ & $178(46.8 \%)$ & $3(0.8 \%)$ \\
\hline POST test phase & $181(33.3 \%)$ & $187(34.4 \%)$ & $186(50.5 \%)$ & $182(49.5 \%)$ & $0(0.0 \%)$ \\
\hline
\end{tabular}

\subsection{Results of the Student Program Evaluation}

The pre-test explored reporting preferences. It revealed the students' marked preference to discuss bullying and cyberbullying incidents with their parents, regardless of whether they were the target or a bystander (if it happened to you: $65.6 \%$, if it happened to someone else: $48.3 \%$ ). Students also indicated preferences for discussing these incidents with friends or siblings (if it happened to you: $54.5 \%$, if it happened to someone else: $35.0 \%$ ). They were less interested in reporting bullying and cyberbullying to other trusted adults (e.g., counselor, relative) (if it happened to you: $32.2 \%$, if it happened to someone else: $33.9 \%$ ) or school personnel (if it happened to you: $28.9 \%$, if it happened to someone else: $38.1 \%$ ). In general, students indicated a stronger preference when they were the target.

These results are consistent with other research and suggest areas for improvement; many studies have focused on the importance of bystander reporting (Coloroso, 2008; Gini, Pozzoli, Borghi, \& Franzoni, 2008; Trach, Hymel, Waterhouse, \& Neale, 2010). The content of the MARC student programming does consistently emphasize the positive actions that bystanders, witnesses, friends, and peers can take in reporting bullying and helping targets.

The post-test saw change in reporting preferences. A few weeks after the assembly, the respondents indicated an increased willingness to discuss bullying and cyberbullying with all possible parties, especially when they were bystanders of cyberbullying incidents. The proportion of students agreeing that they would talk to parents, peers, and adults at school if they witnessed someone being mean online or through text messaging to someone else all increased between the pre- and post-test (Figure 1).

The pre- and post-test results suggest that some factual information in the school assemblies is communicated more successfully than others (Table 5). Several key concepts were successfully increased, including the significance of online privacy ("passwords should be kept private": $+36.3 \%$ ); the loss of control over contents posted online ("once we post something online, it could be there online forever, even if we 'delete' it": $+11.3 \%$ ), and the appreciation of the (occasionally) criminal nature of extreme bullying ("bullying is sometimes a criminal harassment or a civil rights violation": 23.4\%) (Table 5). (Please note that in the state of Massachusetts, bullies have been charged with civil rights violations.) 


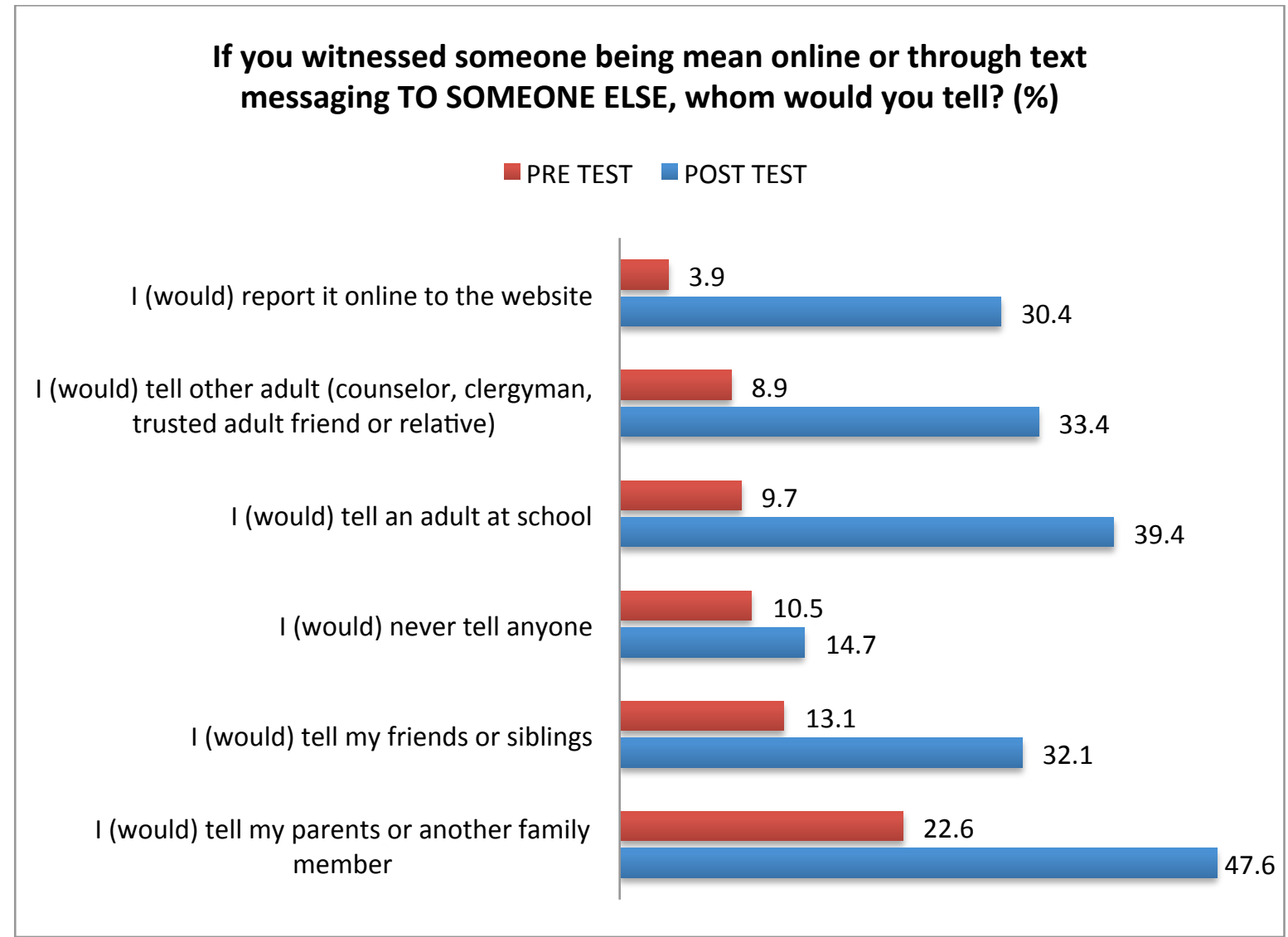

Figure 1 Changes in willingness to report among students

Table 5 Changes in attitudes among students

\begin{tabular}{|l|c|c|c|}
\hline \multicolumn{1}{|c|}{ Statement } & $\begin{array}{c}\text { Do you agree } \\
\text { with the } \\
\text { statement? } \\
\text { Pre-test (n, \%) }\end{array}$ & $\begin{array}{c}\text { Do you agree } \\
\text { with the } \\
\text { statement? } \\
\text { Post-test (n, } \\
\text { \%) }\end{array}$ & $\begin{array}{c}\text { Rate of } \\
\text { development (Pre- } \\
\text { and Post test) }\end{array}$ \\
\hline Bystanders CAN change bullying / cyberbullying incidents at all. & $220(57.9 \%)$ & $256(69.6 \%)$ & $+11.7 \%$ \\
\hline $\begin{array}{l}\text { Bullying is when a person / group uses power to hurt another person } \\
\text { repeatedly. }\end{array}$ & $343(90.3 \%)$ & $328(89.1 \%)$ & $-1.2 \%$ \\
\hline Texting a lot when we are mad can make us feel worse. & $149(39.2 \%)$ & $91(24.8 \%)$ & $-14.5 \%$ \\
\hline Bullying is sometimes criminal harassment or a civil rights violation. & $229(60.3 \%)$ & $308(83.7 \%)$ & $+23.4 \%$ \\
\hline $\begin{array}{l}\text { Once we post something online it could be there online forever, even } \\
\text { if we 'deleted' it. }\end{array}$ & $272(71.6 \%)$ & $305(82.9 \%)$ & $+11.3 \%$ \\
\hline $\begin{array}{l}\text { Passwords should be kept private (not to be shared and should be } \\
\text { changed periodically). }\end{array}$ & $179(47.1 \%)$ & $307(83.4 \%)$ & $+36.3 \%$ \\
\hline $\begin{array}{l}\text { We are less likely to be punished due to violation of law in } \\
\text { cyberspace. }\end{array}$ & $28(7.4 \%)$ & $8(2.1 \%)$ & $+5.3 \%$ \\
\hline \multicolumn{2}{|c|}{ Mean (How much is the development between pre- and post test?) } \\
\hline
\end{tabular}

Factors that showed little or no change included understanding of the conceptual elements of bullying; however, the lack of a shift was largely due to high understanding of the nature of bullying already present in the pretest ("bullying is when a person / group uses power to hurt another person repeatedly": $-1.2 \%$ ). Also, student belief about the low likelihood of violations in cyberspace being detected and punished did not change significantly ("we are less likely to be punished for a violation of law in cyberspace": $+5.3 \%$ ). One piece of 
misinformation actually increased: in the post-test, students were even more likely to deny the escalation of emotion in digital contexts, although the assembly seeks to instruct them in the opposite direction ("texting a lot when we are mad can make us feel worse": $-14.5 \%$ ).

We further tested the effects of the student assembly by correlating post-test values (statements they have learnt through the assembly) with pre-test values (statements that were made by the participants before the assembly). We found significant correlations between knowing the correct definition of bullying and high awareness about online privacy and data concerns ("once we post something online it stays there forever, even we "deleted" it" $\left(\mathrm{r}^{2}=.217 ; \mathrm{p}<.000\right)$, as well as knowing that "bullying was sometimes a criminal harassment" $\left(\mathrm{r}^{2}\right.$ $=.201 ; \mathrm{p}<.000$ ) (see detailed Table in Appendix 2). Students who understood factual knowledge about bullying also understood factual knowledge about online privacy and data and the occasional criminal nature of bullying.

Why did willingness to report increase, particularly to school personnel? MARC's trainers stress the importance of school climate and how significant an effect a bullying/cyberbullying incident may have on the entire community - that is, that the actual impact of such an incident is very broad, despite the fact that it only affects a few persons directly. The students might have, therefore, better understood the significance of involving other community members (such as teachers or other school staff) in the management of bullying and conflicts. Another possibility is that students witness their teachers learning alongside with them during the programming, and that co-learning experience may increase their comfort in reporting to them. In the correlated questions being aware of what constitutes bullying, being aware that bullying is sometimes a criminal harassment, and the lack of privacy online - the pre-test, post-test design makes the most plausible explanation simply that students gained that knowledge during their participation in the MARC program.

Qualitative data (open-ended questions) suggested that the lecture portion of the program was met with a mainly positive response. Not only did the students absorb new knowledge, but they were also successfully mobilized: the MARC student presenters increased their interest in the topic, and gave inspiring advice. The students primarily seemed to appreciate the fact that they got a more detailed general image of the phenomenon and they highlighted the easy-to-follow, practical advice. Some negatives were mentioned, notably, the methodological shortcomings of the student assembly, such as insufficient interactivity or group work, and that they wanted to hear more about how to stop bullying.

\section{Other Qualitative Sources of Feedback and Evaluation}

As mentioned above, part of the anti-bullying legislation passed in Massachusetts in 2010 was a requirement that all school staff be trained in bullying and cyberbullying prevention on a regular basis. Like most of the professional development opportunities offered to schools, MARC faculty trainings are single-session trainings. While this type of in-service training model is very common, single-session trainings are also widely recognized as arguably the least effective way to ensure training transfer and knowledge acquisition (Lauro, 1995). It is no surprise then that feedback from teachers reliably identify the need for ongoing training, recognized as a best practice in professional development (Hunzicker, 2011). In response to MARC's faculty in-services, teachers tend to report a need for more ongoing training, but they also report that the trainings were relevant and useful. Informal feedback gathered has included the following comments:

\footnotetext{
"More than one teacher commented on the fact that this was one of the most productive workshops we have attended. The information and research data presented was both interesting and compelling and has led
} 
to a readjustment of our outlook on bullying and cyberbullying. We appreciate especially the very practical tools and advice you provided for dealing more successfully with various situations in our school."

"The material is research-based with proven results and the program adapts to the needs of the target audience. I appreciate that the presentations incorporate the latest findings and are never perceived as canned."

"I felt that [the faculty training] was informative, presented very useful information and gave practical ideas and suggestions that I can use."

"The presentation was informative and engaging. I feel that, far too often, bully prevention 'solutions' that are presented sound well and good, but are not realistic. On the flip side, your approach and proposed solutions seemed to perfectly match up with what we in the child development field, witness on a regular basis."

"Now that was a meaningful, applicable in-service with a person who knows how to keep things moving AND interesting. I didn't even nod off once!"

It's notable that answers to open-ended questions tend to focus on the two distinctive characteristics of the MARC faculty training: the emphasis on data and research (versus theory), and the practical strategies for dealing with antisocial behaviors. Many teachers expressed a desire for more opportunity for collaboration and time to practice skills. Participants also reported that the trainers (University faculty affiliated with MARC) were well prepared, informative, and understandable and the content was practical and useful. In addition, the material was presented in a way that participants easily understood and the material covered felt relevant to their work with students. This is critical, as one aspect that increases the effectiveness of professional development is its relevance to teachers' daily practice (Garet, Porter, Desimone, \& Yoon, 2001; Hunzicker, 2011; Knowles, 1973).

Students seem to gain knowledge concerning the major issues discussed, particularly about digital privacy and other online behaviors. (In both quantitative and qualitative data, students' focus and retention was often higher when considering digital issues, which may reflect their strong interest in digital communications generally.) Students also frequently report gaining knowledge about how to best handle bullying and cyberbullying situations as they encounter them. Humorously, one student wrote, "I find this a refreshment from all those dumb strategies that only work in musicals." Another student said, "Finally! Not some dumb, 'go be friends with the bully' presentation!" Open-ended feedback about the impact on students is also sought from the adults in their school, and that feedback included the following comments:

"Our entire 7th grade was engaged and the buzz about the energetic presenter was all positive."

"You gave a lot of good information about how kids see things - as opposed to adults. Also, I appreciated learning about the strategies to deal with issues."

"The presenter was amazing! 120 girls totally captivated and engaged. Her information was so current and her presentation was a great blend of teaching and Q \& A. At the end of the event we had great questions from the girls and when I asked the girls if they had learned "at least" one new thing-most every hand went up!"

"Our students were attentive and on target with the message due to M's knowledge, demeanor, control, and sensitivity."

\footnotetext{
1 The entire, unedited text of every piece of written feedback is published on the MARC website in the "Outcomes" section. These are simply informative samples intended to indicate the direction of comments.
} 


\subsection{Presenting Evaluation Data in Eastern Europe}

One of the goals of MARC is to disseminate information about best practices and to help other organizations implement those practices in a resource-efficient manner. As part of Hungary's efforts to consider adapting MARC's model to its schools, MARC was invited to present to local educators in Budapest, Hungary. While the program engendered intense interest, as measured by a high level of attendance at scheduled presentations of the model, many obstacles may remain before this model can be utilized in Eastern or Central Europe. Educators in Hungary appeared to doubt the efficacy of any prevention efforts in this area and still appear to be focusing more on reactionary responses (versus prevention) to the more overt forms of bullying, i.e., physical and verbal attacks (versus more subtle bullying). Educators who attended MARC's talks in Budapest often expressed the opinion that it is unrealistic to expect teachers to make any response to bullying and that even if they did, such responses were unlikely to make any substantial difference.

The efficacy of the high status peer model (older students working with younger students) was met with the same contradictory mix of interest and skepticism. One teacher recounted an experimental program using older students at her school that had very negative outcomes. (It was not clear why.) This is strikingly different from Western countries, particularly the U.S., where peer-on-peer education is widely viewed as highly effective (Dupper, 2010; Tindall \& Black, 2010). The difference may be cultural; some educators described a low level of social trust in post-Soviet bloc societies in Europe, and that may impede the trust and esteem necessary for a successful peer-led program (Wike \& Holzwark, 2008; Pew Research Global Attitude Project, 2007).

Although the high level of interest in MARC's program and its elements was encouraging, the skepticism and disbelief expressed in Eastern Europe about the efficacy of any programming could prove fatal to the adoption of such a University-based program. Prior work with educators, possibly during their own (formative) University training, would need to focus on the development of positive anti-bullying strategies. Before programs such as MARC's are likely to succeed, educators would need to "buy in" to concepts such as the idea that a student could be so altruistic that they would offer help to others, without anything to gain personally; that older students could be trusted advisors for younger children; and that the notion of "community" includes an obligation to take care of one another's needs, both online and in school. It is likely that the adoption of MARC's program would need to begin by assisting Universities with teacher education several years before extending the program out to primary and secondary schools.

\section{Conclusion}

A year-long evaluation of a unique, University-based program in bullying and cyberbullying prevention highlights the success of some of its distinctive characteristics, notably the reliance on research findings, digital issues, the use of high-status peers, and practical strategies. Both quantitative and qualitative data agree that these characteristics are largely more successful than adults anticipate; however, some weaknesses were also identified. Both adults and students cite the need for ongoing, interactive programs, and while they endorsed practical strategies, always wanted more. Furthermore, the program's adoption in Central Europe may require significant preparation, since cultural tendencies towards mistrust and difficulty with the concept of children's altruism might make the positive elements of the program more difficult to implement. Research and field studies are needed on the adaptation techniques and implementation methods in countries where neither social emotional learning, assertive and altruist behavior, nor peer support are an everyday practice at schools. 


\section{References}

Coulter R., Kessel S., Schneider S., O’Donnell L. and Stueve A. (2011). "Cyberbullying, School Bullying, and Psychological Distress: A Regional Census of High School Students”, American Journal of Public Health, Vol. 10, available online at: http://ajph.aphapublications.org/cgi/content/abstract/AJPH.2011.300308v1.

Dupper D. R. (2010). A New Model of School Discipline: Engaging Students and Preventing Behavior Problems, Oxford: Oxford University Press.

Englander E. K. (2012, October 22). "Bullying and cyberbullying in teens: Clinical factors", The American Academy of Child and Adolescent Psychiatry, San Francisco, CA, available online at: https://aacap.confex.com/aacap/2012/webprogram /Session8538.html.

Englander E. (2012). "Research findings: MARC 2011 Survey grades 3-12”, Bridgewater, Massachusetts: Massachusetts Aggression Reduction Center, Bridgewater State University, available online at: http://webhost.bridgew.edu/marc/MARC\% 20REPORT-Bullying\% 20In\%20Grades\%203-12\%20in\%20MA.pdf.

Englander E. (2013). Bullying and Cyberbullying: What Every Educator Needs to Know, Cambridge, Mass.: Harvard Education Press.

Finkelhor D., Turner H., Ormrod R. and Hamby S. (2010). "Trends in childhood violence and abuse exposure: Evidence from 2 national surveys", Archives of Pediatrics \& Adolescent Medicine, Vol. 164, No. 3, pp. 238-242, doi:10.1001/archpediatrics.2009.283

Garet M. S., Porter A. C., Desimone L., Birman B. F. and Yoon S. K. (2001). "What makes professional development effective? Results from a national sample of teachers”, Educational Research Journal, Vol. 38, No. 4, pp. 915-945.

Hasebrink U., Livingstone S., Haddon L. and Ólafsson K. (2009). Comparing Children's Online Opportunities and Risks Across Europe: Cross-national Comparisons for EU Kids Online (2nd ed.), London: London School of Economics and Political Science, EU Kids Online (Deriverable D3.2 for the EC Safer Internet Plus Programme).

Hunzicker J. (2011). "Effective professional development for teachers: A checklist", Professional Development in Education, Vol. 37, No. 2, pp. 177-179.

Knowles M. (1973). The Adult Learner: A Neglected Species, Houston, TX: Gulf Publishing Company.

Lauro D. (1995). "Five approaches to professional development compared", THE Journal, 22, retrieved October 9, 2009, Article originally appeared in the 05/01/1995 issue of THE Journal.

available online at:

http://thejournal.com/Articles/1995/05/01/Five-Approaches-to-Professional-Development-Compared.aspx?p=1.

Livingstone S. and Haddon L. (2009). “Conclusion”, in: S. Livingstone \& L. Haddon (Eds.), Kids Online: Opportunities and Risks for Children, Bristol: University of Bristol (UK): The Policy Press, p. 247.

Lobe B., Segers K. and Tsaliki L. (2009). "The role of parental mediation in explaining cross-national experiences of risk", in: S. Livingstone \& L. Haddon (Eds.), Kids Online: Opportunities and Risks for Children, Bristol: University of Bristol (UK): The Policy Press, pp. 173-186.

Olweus D. (1993). Bullying at School: What We Know and What We Can Do, Oxford; Cambridge USA: Blackwell.

Lenhart A., Madden M., Smith A., Purcell K., Zickuhr K. and Rainie L. (2011). "Pew internet research center study on teens, kindness and cruelty on social network", available online at: http://pewinternet.org/Reports/2011/Teens-and-social-media.aspx.

Pew Research Global Attitude Project, updated Spring, 2013, available online at: http://www.pewglobal.org.

Seybert H. (2011). "Internet use in household and by individuals, 2011", Eurostat, Statistics in Focus, 66/2011, available online at: http://epp.eurostat.ec.europa.eu/cache/ITY_OFFPUB/KS-SF-11-066/EN/KS-SF-11-066-EN.PDF

Staksrud E. (2009). "Problematic conduct: Juvenile delinquency on the internet", in: S. Livingstone \& L. Haddon (Eds.), Kids Online: Opportunities and Risks for Children, Bristol: University of Bristol (UK): The Policy Press, pp. 147-158.

Tindall J. A. and Black D. R. (2010). Peer Programs. An In-Depth Look at Peer Programs: Planning, Implementation and Administration (2nd ed.), New York (NY): Routledge.

Vaillancourt T., Hymel S. and McDougall P. (2003). "Bullying is power”, Journal of Applied School Psychology, Vol. 19, No. 2, pp. 157-176, doi:10.1300/J008v19n02_10.

Van de Vijver F. J. R. and Chasiotis A. (2010). "Making methods meet: Mixed design in cross-cultural research", in: J. A. Harkness, M. Braun, B. Edwards, T. P. Johnson, L. Lyberg, P. Ph. Mohler, B. E. Pennel \& T. W. Smith (Eds.), Survey Methods in Multinational, Multiregional, and Multicultural Contexts, Hoboken (NJ): John Wiley \& Sons, Inc., pp. 455-476.

Virág Gy and Parti K. (2011). "Sweet child in time: Online sexual abuse of children — a research exploration", The Open Criminology Journal, Vol. 4, pp. 71-90, available online at: http://www.benthamscience.com/open/tocrij/ articles/V004/SI0048TOCRIJ/71TOCRIJ.pdf. 
Wike R. and Holzwart K. (2008). "Where trust is high, crime and social corruption are low", April 15, 2008, published under the Pew Research Global Attitude Project, available online at: http://www.pewglobal.org/2008/04/15/where-trust-ishigh-crime-and-corruption-are-low. 